\title{
Dynamic Hyperinflation of a Giant Pulmonary Bulla on Single lung Ventilation can cause Cardiac Arrest: A Rare Case
}

\author{
Ikram Chaudhry*, Ahsan Cheema, Hafsa Abid, Manal Alnami, Zaki Zahher and Hadi Mutari \\ Department of Thoracic surgery and Anesthesia, King Fahad Specialist Hospital Dammam, Saudi Arabia
}

Submission: April 23, 2018; Published: May 11, 2018

*Corresponding author: Ikram Ul Haq Chaudhry, Department of Thoracic Surgery and Anesthesia, King Fahad Specialist Hospital Dammam, Saudi Arabia, Email: drihc007@gmail.com

\begin{abstract}
A 52 year old male presented with history of progressive shortness of breath, no history of cough or haemoptysis. Chest x-ray showed a giant bulla in left hemi thorax. CT scan of chest revealed a more than half of left hemi thorax occupied by a giant bulla. Overall both lungs showed emphysematous changes. He was admitted for video assisted surgical stapling of left lung giant bulla. A double lumen endotracheal tube was inserted and its position was confirmed with fibro-optic bronchoscope. While patient was positioned for left posterolateral thoracotomy suddenly he developed hypotension, bradycardia and near cardiac arrest. Emergency thoracotomy was performed, giant bulla which was hyper dynamically inflated because of mechanical ventilation it was immediately decompressed. Patient was resuscitated successfully and surgical procedure was completed.
\end{abstract}

Keywords: Double lumen tube; Single ventilation; Hyper dynamic inflation; Surgery; Cardiac Arrest.

\section{Introduction}

Hyper dynamic inflation of the lungs has been reported in patients with asthma, chronic obstructive airway disease, emphysematous and transplanted lungs while they are on mechanical ventilation [1]. Unnoticed progressive hyperinflation of a giant lung bulla can cause hemodynamic collapse and cardiac arrest. As the change in the intrathoracic pressure due to hyperinflation is transmitted to great vessels which results in decrease in venous return to the heart, hypotension and decrease cardiac output and ultimately leading to cardiac arrest [2].

Case

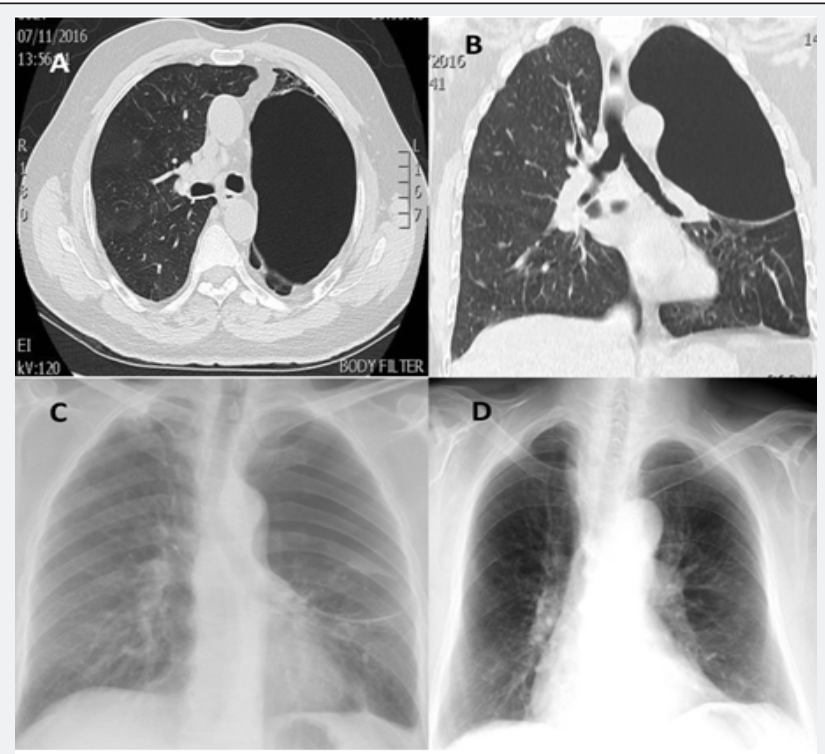

Figure 1: (A) CT Scan of thorax axial view showing a giant left pulmonary bulla. (B) coronal view showing same pathology. (C) Preoperative chest $\mathrm{x}$-rays showing giant left lung bulla. (D) post-operative chest $\mathrm{x}$-ray of the patient. 
A 52 years old man smoker 40/cigarettes per day was admitted with shortness of breath on exertion, no history of cough, loss of weight and appetite. His chest X-ray showed a large bulla in left hemi thorax. Computed tomographic scan (CT) of thorax revealed giant bullae largely occupying the left hemi thorax (Figure 1). Routine blood investigations total white cell count, hemoglobin, renal and liver panels were normal. Preoperative FEV1 was 70\%. At room air his oxygen saturation was 92\%. Arterial blood gas analysis showed pH: 7.37, a PO2 (partial pressure of oxygen) was $65.2 \mathrm{mmHg}$ and $\mathrm{PCO}_{2}$ (partial pressure of carbon dioxide) was $50.18 \mathrm{mmHg}$. As the patient was symptomatic we decided to proceed for bullectomy. Prior to induction of general anesthesia an emergency surgical instruments trolley was prepared in case of any inadvertent event.

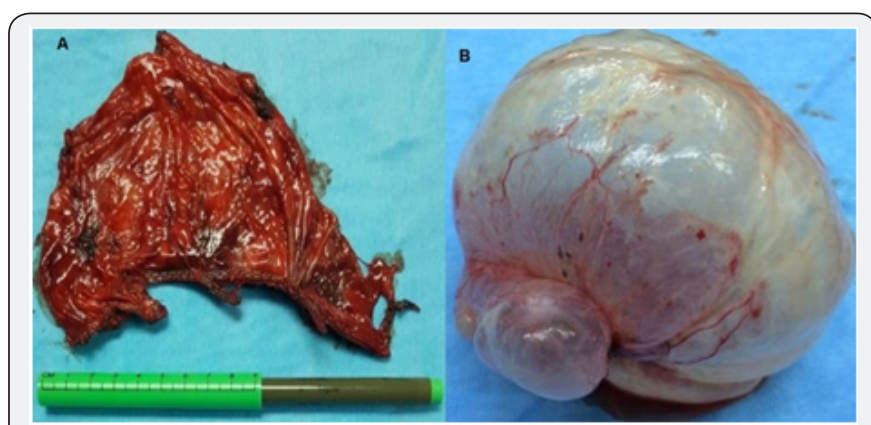

Figure 2: A gross appearance of bulla after resection (B) Bullae inflated with air to demonstrate its size.

He was induced with intravenous propofol $2 \mathrm{mg} / \mathrm{kg}$ and fentanyl 100 microgram. Muscle relaxation was achieved with intravenous rocuronium $0.6 \mathrm{mg} / \mathrm{kg}$. Double lumen endotracheal tube was inserted after adequate relaxation. Position of endotracheal tube was confirmed with fiber optic bronchoscopy to make sure left lung is isolated. Anesthesia was maintained with oxygen-air $\left(\mathrm{Fio}_{2} \mathrm{O} .5\right)$ and sevoflurane. Intraoperative monitoring included ECG, Pulse oxymeter, end tidal carbon dioxide $\left(\mathrm{ETCo}_{2}\right)$, invasive blood pressure monitoring and temperature. Patient was positioned for left posterolateral thoracotomy, suddenly patient became hypotensive BP $60 / 40$, which did not respond to intravenous fluid bolus, phenylephrine and adrenaline but heart rate continue to slow down up to $10-15 / \mathrm{min}$. Anticipating the hyper dynamic inflation of giant bullae compressing the heart emergency thoracotomy through $5^{\text {th }}$ intercostal space was performed and giant bulla almost occupying the left hemi thorax was incised for decompression, immediately patient's hemodynamics start improving, heart rate came back to 100 beat per minute and blood pressure 100/60 mmHg. Mechanical ventilation was resumed and double lumen endotracheal tube was repositioned under flexible bronchoscopy guidance. Once the patient was stable, bullae were resected using tristapler and inferior pulmonary ligament was divided to mobilize lower lobe to fill the hemi thorax (Figure 2). Chest was closed as a routine in layers and $32 \mathrm{Fr}$ chest drain was inserted. Patient was transferred to ICU and was extubated next morning, latter on he was transferred to the ward. He was discharged for further follow up in outpatient.

\section{Discussion}

Double lumen endotracheal intubation for single lung ventilation is required in a lot of thoracic surgical procedures for better surgical exposure and protection of contralateral lung from contamination and spillage of blood in case of hemoptysis. Single lung ventilation is very challenging for the anesthetist to maintain the oxygenation and hemodynamic stability throughout the surgical procedure, as this creates a large intrapulmonary shunt which can cause hypoxia and end organ damage. Excessive positive end expiratory pressure, hypoxia, hypercarbia and hypovolumia may contribute to high pulmonary vascular resistance of dependant lung which increase the shunt fraction. Different sizes of double lumen tubes are available ranging from $27 \mathrm{~F}$ to $41 \mathrm{~F}$. Correct size of double lumen tube almost completely seal the bronchial lumen without inflation of cuff. Small tube with high inflation pressure and large tube in small bronchus can cause mucosal damage [3]. Anesthesiologist confirms the correct position of endotracheal tube with bronchoscopic examination. As this has proved that $48 \%$ of tubes are usually malpositioned, which is very hazardous. Apart from difficult surgical exposure this can cause impaired ventilation, hypoxia, gas trapping, pneumothorax and contamination of other lung [4]. Pulmonary bullae are abnormal dilatation of air spaces distal to terminal bronchiole and are greater than two centimeter in distended state. When the bullae occupy more than half of the hemi thorax they are called giant bullae and commonly seen in patients with paraseptal emphysema and progressive fibrotic lung disease [5]. These bullas can remain asymptomatic they are treated conservatively. Surgical treatment is reserved for giant bullae occupying more than thirty percent of hemi thorax causing compression of adjacent healthy lung to the extent that patient is having incapacitating dyspnea or associated complications like, infection, hemorrhage rupture of bulla leading to pneumothorax [6]. In patients with bullous lung disease induction of general anesthesia and proper placement of double lumen tube, maintaining hemodynamic stability and blood gas chemistry throughout the surgical procedure is difficult task. Such patients need high airway pressure and large tidal volume to maintain normal arterial carbon dioxide partial pressure which is injurious to the lungs. General anesthesia and endotracheal intubation in patients with emphysematous and bullous lung disease can cause hyper dynamic inflation and enlargement of bullae leading to cardiovascular compromise and cardiac arrest. Rarely this clinical condition is diagnosed in early stage usually they are diagnosed late or on autopsy reports $[7,8]$. The main contributing factors to cause hyper dynamic inflation are a large tidal volume, short expiratory time before the next breath is initiated and chronic obstructive airway disease. When minute ventilation is higher to prevent passive exhalation of delivered tidal volume within the given expiratory period, this may create a dynamic hyperinflation and increased auto peep 
$[9,10]$. Pathophysiological consequences of this are deleterious both on the gas exchange and cardiovascular system. Distended bullae compress the residual lung leading to compression of alveoli and pulmonary capillaries which impair the gas exchange due to increase in dead space [11].

As bulla size increases with each breath the intrathoracic pressure rises too, which compress the big veins and eventually reduce the cardiac out leading to cardiac arrest. Furthermore due to giant size and hyper dynamic inflation pulmonary vascular resistance and right ventricular after load increases this compromises the left ventricular function. Hyper dynamic inflation should be suspected if there is sudden hypotension, oxygen desaturation, pulses paradoxes and distended neck veins when patient is connected to mechanical ventilation after induction of anesthesia. Although few methods have been reported in medical literature to quantify the hyperdynamic inflation including if there is persistent expiratory flow at the end of expiration on flow volume loop, collecting expired gas in ventilator bellow, increased peak and plateau pressure during volume controlled ventilation decrease in tidal volume during pressure controlled ventilation and increase in auto peep. None of these methods is perfectly accurate and applicable $[12,13]$.

Dynamic hyperinflation can be prevented by early recognition and ventilator manipulation to adjust low tidal volume, low respiratory rate and inspiratory, expiratory ratio that favors prolonged expiration. During perioperative period permissive hypercarbia and hypoventilation without compromising the FiO2 is a common practice. High PEEP is dangerous in such cases. Nitrous oxide should not be used because this is 34 times more diffusible than nitrogen and can lead to expansion of airfilled cavities.

\section{Conclusion}

Early recognition and immediately disconnecting the patient from ventilator and emergency thoracotomy and decompression of bullae with pharmacological support for the near cardiac arrest saved his life. Early recognition of hyper dynamic inflation of giant lung bulla is very important as this can lead to significant hemodynamic instability and may precipitate cardiac arrest, which may ultimately cause death.

\section{References}

1. Yin Peigang, John J Marini (2002) Ventilation of patients with asthma and chronic obstructive airway disease. Curr Opin Crit Care 8(1): 7076.

2. Myles PS, Madder H, Morgan EB (1995) Intraoperative cardiac arrest after unrecognized dynamic hyperinflation. Br Anesthe 74(3): 340342 .

3. Brian L Marasigan, Roy Sheinbaum, Gregory B Hammer, Edmond Cohen (2013) Separation of two lungs: Benumof and Hagbergs Airway Management. ( $3^{\text {rd }}$ edn), pp. 549-568.

4. Ogilvie C (1959) Catterall Patterns of disturbed lung function in patients with emphysematous bullae. Thorax 14: 216-224.

5. Greenberg JA, Singhal S, Kaiser LR (2003) Giant bullous lung disease: evaluation, selection, techniques and outcome. Chest Surg Clin N Am 13(4): 631-649.

6. Vigneswaran WT, Toesend ER, Fountaun SW (1992) Surgery for bullous disease of lung. Eur J Cardiothorac Surg 6(8): 427-430.

7. Myles PS, Madder H, Morgan EB (1995) Intraoperative cardiac arrest after unrecognized dynamic hyperinflatation. Br J Anesth 74: 340-342.

8. Rogers Pl, Schlichtig R, Miro A, Pinsky M (1991) Auto-PEEP during CPR: an occult cause of electromechanical dissociation? Chest 99(2): 493-493.

9. Canacher ID (1998) Dynamic hyperinflation-the anesthetist applying a tourniquet to the right heart. Br J Anesth 81(2): 116-117.

10. Tan IK, Bhatt SB, Tam YA, Oh Te (1993) Effects of PEEP on dynamic hyperinflation in patients air flow limitation. Br J Anesth 70(3): 267 272.

11. Bergma NA (1972) Intrapulmonary gas trapping during mechanical ventilation at rapid frequencies. Anesthesiology 37(6): 626-633.

12. Myles PS, Ryder IG, Weeks AM, Williams TM, Esmore DS (1997) Diagnosis and management of dynamic hyperinflation during lung transplantation. J Cardiothorac Vas Anesth 11(1): 100-104.

13. Marseu K1, Slinger P, de Perrot M, McRae K, Ma M (2011) Dynamic hyperinflation and cardiac arrest during one lung ventilation. Can J Anesth 58(4): 396-400

Your next submission with Juniper Publishers
will reach you the below assets
- Quality Editorial service
- Swift Peer Review
- Reprints availability
- E-prints Service
- Manuscript Podcast for convenient understanding
- Global attainment for your research
- Manuscript accessibility in different formats
( Pdf, E-pub, Full Text, Audio)
- Unceasing customer service
Track the below URL for one-step submission
https://juniperpublishers.com/online-submission.php

